\title{
Virtual Screening of Indonesian Herbal Database as a-Amino-3- Hydroxy-5-Methyl-4 Isoxazolepropionic Acid (AMPA) Antagonist
}

\author{
Rezi Riadhi Syahdi, Chindy Dwi Martinah, Arry Yanuar*
}

\section{Rezi Riadhi Syahdi, Chindy Dwi Martinah, Arry Yanuar*}

Biomedical Computation and Drug Design Laboratory, Faculty of Pharmacy, Universitas Indonesia, Depok, INDONESIA.

\section{Correspondence}

\section{Arry Yanuar}

Biomedical Computation and Drug Design Laboratory, Faculty of Pharmacy, Universitas Indonesia, Depok, INDONESIA E-mail: arry.yanuar@ui.ac.id

History

- Submission Date: 10-02-2019;

- Review completed: 12-04-2019;

- Accepted Date: 24-05-2019.

DOI : 10.5530/pj.2019.11.187

Article Available online http://www.phcogj.com/v11/i6

Copyright

(C) 2019 Phcogj.Com. This is an openaccess article distributed under the terms of the Creative Commons Attribution 4.0 International license.

\begin{abstract}
Objective: Ischemic stroke is one type of circulatory disturbance caused by blood clots that block blood flow to the brain. One of the impact of ischemia is nerve cell damage due to excitotoxicity. Inhibition of the ionotropic glutamate receptor such as the AMPA receptor, becomes an essential approach to the treatment of ischemia. This study aims to explore the possibility of an Indonesian herbal compound as an AMPA receptor antagonist. Methods: In this study, virtual screening of 2233 herbal compounds was performed by docking method using AutoDock to find the antagonist candidate of AMPA receptor from Indonesian herbal database. The virtual screening method was validated by an area under curve (AUC) of the ROC curve and enrichment factor (EF). Lipinski's Rule of Five was used to filter the screening result. Results: The validation of virtual screening result showed that AUC was 0.9385 and EF $1 \%$ was 23.5550. The screening result of Indonesian herbal database showed top five compound sanggenol $\mathrm{O}$, blazeispirol $\mathrm{X}$, progesterone, nimolicinol and boeravinone $\mathrm{F}$ (-8.51 -8.39; -8.19; -8.17; -8.08 kcal/mol, respectively) and have interaction with TYR61 and THR91 residues of AMPA receptor. Conclusion: Five compounds of the Indonesia herbal database were shown as hits of AMPA receptor antagonist based on the docking method.
\end{abstract}

Key words: AMPA receptor, AutoDock, Herbal plants, Neuroprotective, Virtual screening.

\section{INTRODUCTION}

In 2012, WHO reported about 6.7 million deaths in this world caused by stroke. ${ }^{1}$ And it was expected to rise to 23.3 million deaths by $2030 .^{2}$ Stroke was a cardiovascular disease caused by blood supply disruption to the brain due to rupture of blood vessels (hemorrhagic) or blockage of blood vessels (ischemic). An ischemic stroke, which caused by a blood clot that blocks blood flow to the brain, more frequent which amounted to $87 \%$ of all strokes. ${ }^{3}$

The previous study reported that stroke disability rate reaches $65 \% .{ }^{4}$ Disability occurs because the brain's nerve cells were susceptible to the lack of oxygen, leads to the cerebral hypoxia. When hypoxia occurs, ROS levels were increased and cause the degradation of lipid membranes and enzymes as well as DNA damage. Moreover, the synthesis of HIF-1 and BDNF decreases during the development of hypoxia. Damage to nerve cells that occur is irreversible. Thus, it takes a neuroprotective agent to protect brain nerve cells from damage. ${ }^{5}$ During this time, neurologic complications of ischemic stroke were overcome by administration of anticonvulsant agents. ${ }^{6}$

Glutamate was the major excitatory neurotransmitter in the central nervous system. In ischemia condition, nerve cells undergo activation and induce the released of glutamate in large quantities resulting in excessive stimulation of glutamate receptors.

This can cause dysregulation of AMPA receptors which can result in nerve cell death, called excitotoxicity. ${ }^{7}$ Inhibition of the ionotropic glutamate receptor becomes an essential approach to the treatment of brain ischemia. On the other hand, the inhibitor of the NMDA subunit receptor was known to have side effects, (especially the psychotomimetic). None of the NMDA receptor inhibitors succeeds in clinical trials. AMPA receptor inhibitors were not reported to have psychotomimetic effects. Therefore, AMPA receptors can be the target choice for cerebral ischemic drugs. ${ }^{8}$ Among the developed AMPA receptor antagonist which accepted in the market was the only perampanel. The number of failures was due to the developed AMPA receptor antagonists inducing severe neurological side effects in epileptic animal models. ${ }^{9}$

Furthermore, herbal plants also played important role in treatment. Currently, there was a database of chemical compounds of Indonesian herbal which can be accessed through www.herbaldb.farmasi. ui.ac.id. ${ }^{10}$

Previous study about AMPA receptor targets against quinazolinedione sulphonamide derivatives as competitive antagonists has been performed using molecular docking. ${ }^{11}$ However, molecular docking of Indonesian herbal databases in competitive AMPA receptor antagonists has never been conducted. Therefore, molecular docking of Indonesian herbal compounds was performed for virtual screening and the results of candidate compounds from Indonesian herbal could be used as active compounds in the further research to be an AMPA receptor antagonist. 


\section{MATERIALS AND METHODS}

\section{Hardware}

The hardware used two computers with following specifications. The first computer has CPU Intel $^{\star}$ CoreTM i5-2450M (Intel ${ }^{\circledR}$ CoreTM, $^{\circ}$

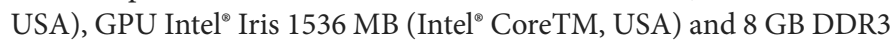
of RAM directly connected to the internet. This computer has the $\mathrm{X}$ Yosemite 10.10 operating system. Monitor (LG, South Korea), mouse and keyboard (Apple Inc., USA). The second computer has processor 2.2 GHz AMD A4-9210 Radeon R3 (AMD Inc., USA), 4 Compute Cores 2C + 2G, GPU AMD Radeon R3 Graphics (AMD Inc., USA), 4 GB DDR4 RAM. This computer has Windows 10 Home Single Language operating system.

\section{Software}

The softwares were PyRx 0.9.7 (The Scripps Research Institute, USA), AutoDock Tools 1.5.6 (The Scripps Research Institute, USA), AutoDock 4.2, AutoDock Vina, MarvinSketch, OpenBabel 2.4.0, KNIME 3.5.1, UCSF Chimera 1.12 and LigandScout 4.1.2.

\section{Structure three-dimensional of ligands}

Ligands consist of positive control compounds, negative control compounds and herbal compounds. Positive control and negative control compounds were downloaded from DUD-E which can be accessed through www.dude.docking.org. Perampanel and cocrystal ligand 08W (Figure 1) were added to be a positive control. Herbal compounds were obtained from Indonesian herbal database (HerbalDB) and its renewal. This database had total 2233 active compounds.

\section{Structure three-dimensional of macromoleculer}

The three-dimensional structure of AMPA receptor was downloaded from RCSB PDB which can be accessed through www.rcsb.org. This macromolecule had PDB ID 3 UA8 and resolution $1.9 \AA$ (Figure 2).

\section{Preparation of ligands}

The structure of herbal compounds can be downloaded from HerbalDB or KNApSAcK and created manually using MarvinSketch. Then the compounds were saved in ${ }^{\star}$.mol2. Positive controls and negative controls were downloaded from the Directory of Useful DecoysEnhanced (DUD-E) in the *.mol2.gz.

\section{Preparation of macromolecule}

The three-dimensional structure of the AMPA receptor was downloaded from the Protein Data Bank site (www.rcsb.org). The structure chosen based on the inclusion criteria which were from the organism Homo sapiens (human), had good resolution and formed a complex with the ligand. The selected macromolecule has PDB ID 3 UA8 and the ${ }^{\star}$.pdb format was downloaded.

\section{Optimization of ligands}

The file ${ }^{*}$.mol2.gz of positive and negative control compound was converted to ${ }^{*}$.pdbqt accompanied by the addition of polar hydrogen atom using the OpenBabel command in the terminal. Then, the ${ }^{*}$.pdbqt file was extracted and converted into ${ }^{*}$.pdbqt format. The optimization of the herbal compound was performed using MarvinSketch. Then, herbal compounds were gifted force field mmff94 and minimization of energy.<smiles>N#Cc1ccccc1-c1cc(-c2ccccn2)cn(-c2ccccc2)c1=O</smiles>

Perampanel<smiles>CNC(=O)c1cn(-c2cc3c(=O)n(NS(C)(=O)=O)c(=O)[nH]c3cc2C(F)(F)F)cn1</smiles>

Cocrystal ligand 08W

Figure 1: Structure 2D of perampanel (left) and cocrystal ligand 08W (right).

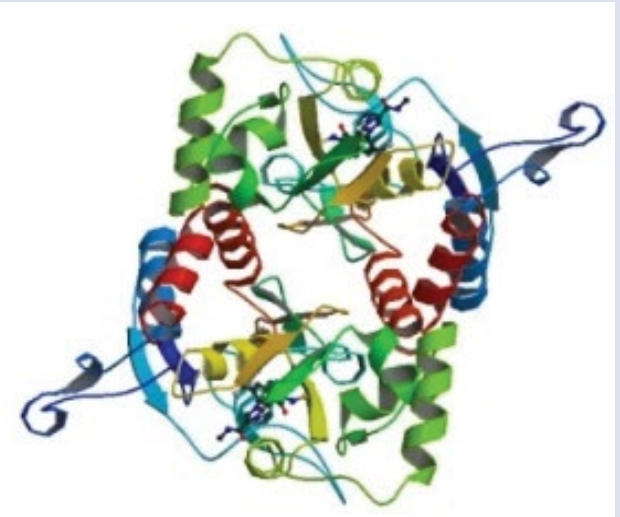

Figure 2: Structure 3D of macromolecule 3UA8. 


\section{Optimization of macromolecule}

Optimization of macromolecule was performed using AutoDock Tools. Macromolecule was separated from ligands for binding sites to be used and non-standard residues such as waters, metals and others were separated in aims not to disrupt the docking. The optimization was performed by adding a polar hydrogen atom and adding a partial charge of Gasteiger Charge. The result was saved in ${ }^{*}$.pdb and was converted to ${ }^{*}$.pdbqt format.

\section{Optimization of docking method}

The optimization of the docking method was performed by redocking the cocrystal ligand from macromolecules. The results should have RMSD below $2 \AA$ and the binding free energy should have more negative. The redocking was performed using AutoDock and AutoDock Vina parameters. The grid box with the best value will be used as a grid in the validation.

\section{Validation of virtual screening method}

Validation of a virtual screening method was performed by docking positive and negative control compounds on target macromolecules. Validation was performed using AutoDock and AutoDock Vina. Validation results were determined from the value of ROC and EF. The docking was performed on the binding sites and the grid was similar to the optimization results. The AutoDock and AutoDock Vina parameters were made varying to obtain the best parameter screening. The AutoDock parameters were grid box dimensions and evaluation of maximum energy values, while the AutoDock Vina parameters were grid box dimension and exhaustiveness.

\section{Virtual screening}

Virtual screening was performed by docking the herbal compound on the cocrystal ligand binding site using AutoDock and AutoDock Vina. The results were the interaction with the compound (ligand) towards the target macromolecule and binding energy. The virtual screening results were sorted by binding energy from the smallest to the largest.

\section{Evaluation based on Lipinski's rule of five}

The result of virtual screening was evaluated by Rule of Five, whether the compound violates the ROF or not. Evaluation ROF using KNIME software. The selected compounds which had score 0 of ROF.

\section{Visualization and analysis of protein-ligand interaction}

The results of virtual screening from AutoDock $\left({ }^{*} . \mathrm{dlg}\right)$ and AutoDock Vina $\left({ }^{*}\right.$.pdbqt) were converted to ${ }^{*}$.pdb that could enable to visualize protein-ligand interactions using LigandScout.

\section{RESULTS}

\section{Optimization of docking method}

The docking was performed at the coordinate of the binding site $\mathrm{x}$ $=45.69 ; \mathrm{y}=35.74 ; \mathrm{z}=9.968$. An analysis of RMSD and binding free energy obtained a good value of RMSD which was below $2 \AA$, whereas the value of binding free energy showed more negative which was better because the energy required ligands to bind to the receptor becomes lower. The results of redocking using AutoDock can be seen in Table 1 while using AutoDock Vina can be seen in Table 2.

\section{Validation of virtual screening method}

The docking parameter was varied to produce lower negative binding energy; value of area under curve (AUC) higher than 0.5 and value of Enrichment Factor (EF) higher than 1. However, since the actives and decoys of this research were from DUD-E, the AUC and EF of DUD-E were also considered. The AUC and EF of this study should exceed the AUC and EF of DUD-E so that the docking method may be better than the DUD-E. The values of ROC and EF DUD-E were 0.7065 and 22.8, respectively.

The result of validation by using AutoDock showed all lines of the ROC curve were above the random value line (Figure 3). Based on Table 3, the values of AUC and EF of this study have exceeded the AUC and EF of DUD-E values. Virtual screening using dimension $80 \times 80 \times 80$ of grid box showed the most EF $1 \%$ and sort the active compounds most effectively. This result showed for virtual screening using AutoDock $80 \times 80 \times 80$.

The results of validation using AutoDock Vina can be seen in Figure 4 that all lines of the ROC curve were above the random value line.

Based on Table 4, it showed that the AUC of this study had exceeded the AUC of DUD-E, while the EF of this study has not exceeded the EF of DUD-E.

Therefore, the virtual screening method using AutoDock Vina was less good. So virtual screening was not performed by using the AutoDock Vina parameter, but only the AutoDock parameter.

\section{Virtual screening}

Virtual screening was performed on 1412 ligands from HerbalDB and 821 ligands from the updated Indonesian herbal, so the total was 2233 ligands. Docking was performed only using AutoDock on PyRx. The used parameters were (1) coordinate binding site $\mathrm{x}=45.69$; $\mathrm{y}=$

Table 1: The results of cocrystal ligand $08 \mathrm{~W}$ redocking using AutoDock, ranked by lowest binding energy

\begin{tabular}{ccc}
\hline Grid Box (Unit) & Binding Energy / $\Delta \mathrm{G}$ (kcal/mol) & RMSD (Å) \\
\hline $40 \times 40 \times 40$ & -8.57 & 0.54 \\
$50 \times 50 \times 50$ & -8.47 & 0.56 \\
$70 \times 70 \times 70$ & -8.16 & 0.32 \\
$80 \times 80 \times 80$ & -8.33 & 0.62 \\
$85 \times 85 \times 85$ & -8.29 & 0.27
\end{tabular}

Table 2: The results of cocrystal ligand $08 \mathrm{~W}$ redocking using AutoDock Vina, ranked by lowest binding energy

\begin{tabular}{ccc}
\hline Grid Box (Å) & $\begin{array}{c}\text { Binding Energy / } \Delta \mathrm{G} \\
(\text { kcal/mol) }\end{array}$ & $\operatorname{RMSD}(\AA)$ \\
\hline $15 \times 15 \times 15$ & -9.1 & 0.32 \\
$18.75 \times 18.75 \times 18.75$ & -9.4 & 0.45 \\
$26.25 \times 26.25 \times 26.25$ & -9.3 & 0.44 \\
$30 \times 30 \times 30$ & -9.1 & 0.30 \\
\hline
\end{tabular}

Table 3: The calculation results of AUC and EF validation using AutoDock.

\begin{tabular}{cccccc}
\hline Grid Box & AUC & EF 1\% & EF 5\% & EF 10\% & EF 20\% \\
\hline $40 \times 40 \times 40$ & 0.9315 & 16.7500 & 19.3034 & 9.5170 & 5.1864 \\
$50 \times 50 \times 50$ & 0.9400 & 11.3063 & 16.6526 & 10.4903 & 4.7966 \\
$70 \times 70 \times 70$ & 0.9253 & 11.3063 & 10.9922 & 8.5823 & 5.3839 \\
$80 \times 80 \times 80$ & 0.9385 & 23.5550 & 14.2375 & 9.0450 & 4.9906 \\
$85 \times 85 \times 85$ & 0.9220 & 23.5550 & 12.0279 & 8.1287 & 4.9906 \\
\hline
\end{tabular}

Table 4: The calculation results of AUC and EF validation using AutoDock Vina.

\begin{tabular}{|cccccc|}
\hline Grid Box & AUC & EF 1\% & EF 5\% & EF 10\% & EF 20\% \\
\hline $15 \times 15 \times 15$ & 0.8624 & 6.8523 & 4.0379 & 3.6687 & 3.6687 \\
$18.75 \times 18.75 \times 18.75$ & 0.8581 & 6.8523 & 4.7966 & 3.3059 & 3.3059 \\
$26.25 \times 26.25 \times 26.25$ & 0.8453 & 6.8523 & 4.0379 & 3.3059 & 3.1269 \\
$30 \times 30 \times 30$ & 0.8455 & 3.1406 & 4.0379 & 3.3059 & 3.3059 \\
\hline
\end{tabular}




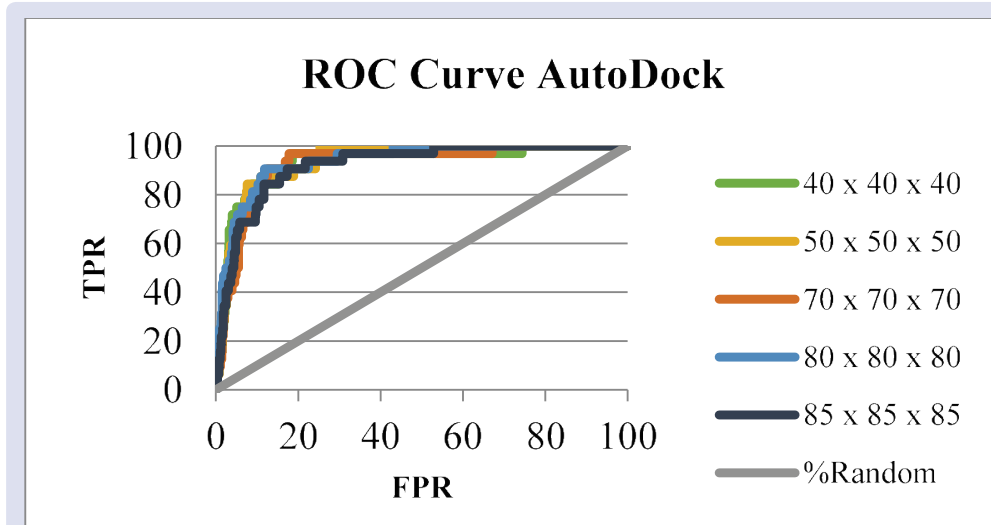

Figure 3: $\mathrm{ROC}$ curve of validation result using AutoDock. $X$ axis shows percentage of false positive rate (FPR) and $Y$ axis shows percentage of true positive rate (TPR) screened

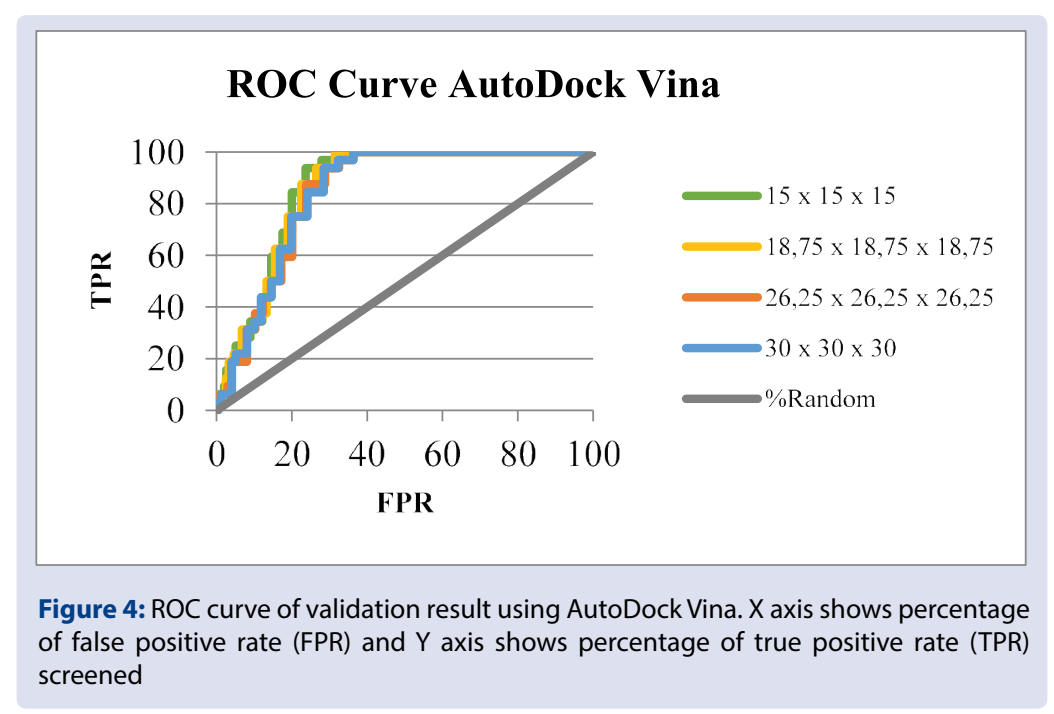

35.74; $\mathrm{z}=9.968$; (2) dimension of grid box was $80 \times 80 \times 80$; (3) spacing $0.375 \AA$; (4) GA run 10; (5) maximum number of energy evaluations 250.000 (short); (6) and number of generation algorithms 27.000. The results of the virtual screening showed in Table 5. Candidates of active compounds had the value of binding energy was $\leq-8.0 \mathrm{kcal} / \mathrm{mol}$ which has been included quite well.

\section{Evaluation based on Lipinski's rule of five}

The evaluation of ROF was performed on 31 candidate compounds having the lowest binding energy to obtain candidate compounds that have good permeability. The selected compounds were compounds that not violate the ROF.

According to Christopher A. Lipinski, the poor permeability when: the molecule had more than 5 hydrogen bond donors and more than 10 hydrogen bond acceptors, the molecular weight was more than $500 \mathrm{Da}$ and $\log \mathrm{P}$ was more than 5 . Moreover, rotatable bond count more than 10 was also a rule violation. ${ }^{12}$

In the Table 5, ROF scores indicated the number of violations; score 0 stated no violation. The greater ROF score, the more ROF violations. N/A indicated the absence of information about the determination of the ROF because of the mismatch between the smiles format with the chemical structure. One or two in five rules were violated which was molecular weight, $\log \mathrm{P}$ and $\mathrm{RBC}$ which exceeds the rules. This will affect the poor permeability.
From the results of ROF evaluation, obtained five compounds that have a score of 0 and shown in Table 6. Since the AMPA receptor was in the brain, the delivery of drugs will be more efficient if it can penetrate the blood-brain barrier. Drugs can penetrate the blood-brain barrier if drugs had $\mathrm{BM}<400 \mathrm{Da}$ and form $<8$ hydrogen bonds. ${ }^{13}$ Therefore, progesterone and boeravinone $\mathrm{F}$ potentially can penetrate the bloodbrain barrier.

\section{Visualization and analysis of protein-ligand interaction}

Visualization of screening results using LigandScout aims to show the interaction between herbal compounds with amino acid residues in two-dimensional and three-dimensional forms. Based on previous research, amino acid residues that have potential as active sites with competitive antagonistic effects on AMPA receptors include GLU402, TYR450, PRO478, LEU479, THR480, ARG485, THR686, GLU705 and SER654. ${ }^{12}$ The macromolecule-ligand interaction in the previous study had differences with PDB ID 3UA8 in numbers of amino acid residue.

However, the amino acid residue of the previous study correlated with amino acid residues of PDB ID 3UA8. According to PDB ID 3UA8, amino acid residues at active sites include GLU13, TYR61, PRO89, THR91, ARG96 and THR174. For more details, the conversion of the number of amino acid residue in the previous study with PDB ID 3UA8 shown in Table 7. Furthermore, the interaction of compounds with the amino acid residues presented in Table 8 . These results showed that the five candidate compounds potentially had competitive AMPA receptor 
Table 5: The results of virtual screening of herbal compound using AutoDock.

\begin{tabular}{|c|c|c|c|c|}
\hline Compound ID & Compound & Target & ROF Score & Binding Energy \\
\hline sh0246 & Katsumadain B & $3 \mathrm{UA} 8$ & 1 & -9.45 \\
\hline $\operatorname{sh} 0134$ & Acacetin 7-(2"-acetylglucoside) & $3 \mathrm{UA} 8$ & 1 & -8.72 \\
\hline M00014245 & Sanggenol O & 3UA8 & 0 & -8.51 \\
\hline M00003558 & Ursolic acid & $3 \mathrm{UA} 8$ & N/A & -8.44 \\
\hline M00003597 & Yamogenin & $3 \mathrm{UA} 8$ & 1 & -8.43 \\
\hline M00002026 & Carpaine & 3UA8 & 1 & -8.42 \\
\hline $\operatorname{sh} 0286$ & $\begin{array}{c}\text { 5alpha,8alpha-Epidioxyergosta- } \\
\text { 6,22-dien-3beta-ol }\end{array}$ & $3 \mathrm{UA} 8$ & 2 & -8.41 \\
\hline $\operatorname{sh} 0130$ & Blazeispirol X & 3UA8 & 0 & -8.39 \\
\hline M00025595 & (-)-2-Norlimacine & 3UA8 & 1 & -8.36 \\
\hline M00007133 & Rubranine & $3 \mathrm{UA} 8$ & 1 & -8.30 \\
\hline $\operatorname{sh} 0295$ & Markogenin & 3UA8 & 1 & -8.27 \\
\hline M00032465 & Ursonic acid & $3 \mathrm{UA} 8$ & N/A & -8.25 \\
\hline M00000015 & Gibberellin A15 & 3UA8 & N/A & -8.24 \\
\hline M00002800 & Cassiamin C & 3UA8 & 2 & -8.24 \\
\hline M00025036 & dl-Fangchinoline & 3UA8 & 2 & -8.24 \\
\hline M00034649 & Progesterone & 3UA8 & 0 & -8.19 \\
\hline $\operatorname{sh} 0094$ & $a$-amyrenone & 3UA8 & 1 & -8.18 \\
\hline M00001070 & Morusin & $3 \mathrm{UA} 8$ & 1 & -8.18 \\
\hline M00036185 & Nimolicinol & $3 \mathrm{UA} 8$ & 0 & -8.17 \\
\hline M00000490 & Yuehchukene & 3UA8 & 1 & -8.14 \\
\hline M00021221 & Platanic acid & 3UA8 & N/A & -8.14 \\
\hline $\operatorname{sh} 0288$ & Sarsasapogenin & 3UA8 & 1 & -8.09 \\
\hline M00019405 & Boeravinone $\mathrm{F}$ & $3 \mathrm{UA} 8$ & 0 & -8.08 \\
\hline M00019604 & Oleanolic acid & $3 \mathrm{UA} 8$ & N/A & -8.06 \\
\hline sh0095 & $\beta$-amyrenone & 3UA8 & 1 & -8.05 \\
\hline M00014275 & Leucadenone B & $3 \mathrm{UA} 8$ & 1 & -8.05 \\
\hline M00001919 & Tetrandrine & $3 \mathrm{UA} 8$ & 2 & -8.04 \\
\hline M00005728 & Myricetin 3-galactoside & 3UA8 & 1 & -8.04 \\
\hline sh0050 & Acetylursolic acid & 3UA8 & 2 & -8.02 \\
\hline $\begin{array}{l}\text { M00006698 } \\
\text { M00009049 }\end{array}$ & $\begin{array}{l}\text { Myrtillin } \\
\text { Cassiaflavan-(4alpha-6)- } \\
\text { epiafzelechin }\end{array}$ & $\begin{array}{l}\text { 3UA8 } \\
\text { 3UA8 }\end{array}$ & $\begin{array}{l}1 \\
1\end{array}$ & $\begin{array}{l}-8.00 \\
-8.00\end{array}$ \\
\hline
\end{tabular}

N/A: Not available

Table 6: List of herbal compounds complying with Lipinski rules.

\begin{tabular}{|c|c|c|c|c|c|c|c|c|}
\hline Compound & Origin Herbal & 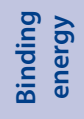 & $\sum_{\Sigma}^{3}$ & $\begin{array}{l}\text { 品 } \\
\text { }\end{array}$ & $\begin{array}{l}\stackrel{0}{\underline{I}} \\
\text { }\end{array}$ & $\underset{\mathscr{\infty}}{\cup}$ & $\begin{array}{l}\text { 함 } \\
\frac{3}{x}\end{array}$ & 峁 پँّ \\
\hline Sanggenol O & Morus australis & -8.51 & 420.157 & 6 & 2 & 7 & 4.117 & 0 \\
\hline Blazeispirol X & Agaricus blazei & -8.39 & 438.277 & 4 & 2 & 8 & 4.086 & 0 \\
\hline Progesterone ${ }^{*}$ & Allium cepa; Solanum tuberosum & -8.19 & 314.225 & 2 & 0 & 4 & 4.826 & 0 \\
\hline Nimolicinol & Azadirachta indica & -8.17 & 482.230 & 7 & 1 & 10 & 2.270 & 0 \\
\hline Boeravinone $\mathrm{F}^{*}$ & Boerhavia diffusa; Mirabilis jalapa & -8.08 & 326.043 & 7 & 3 & 4 & 3.580 & 0 \\
\hline
\end{tabular}

*: Potentially penetrate the blood-brain barrier.

antagonist because they had some interaction with the amino acid residues on the active site according to the previous study. In addition, most compounds bind to TYR61 and THR91, that might indicate they played an important role in the site active of competitive AMPA receptor antagonist.

\section{DISCUSSION}

Macromolecule 3 UA8 is a structure of the GRIA2 subunit of the AMPA receptor which binds to the ligand cocrystal 08W (6-amino quinazolinedione) in the A chain. This ligand acted as a competitive AMPA receptor antagonist. Therefore, the determination of coordinate of the binding site was performed by placed the grid box in the centre on the ligand.
The result of the ROF evaluation showed the five candidate compounds had score 0 and can potentially have good permeation, which was Sanggenol O (Figure 5), Blazeispirol X, Progesterone, Nimolicinol and Boeravinone $\mathrm{F}$.

Sanggenol O was a flavonoid which isolated from the roots of Morus australis. ${ }^{14}$ This plant came from the family Moraceae. Morus australis grows a lot in West Java. Blazeispirol X was a new blazeispirol derivative which isolated from mycelia Agaricus blazei. ${ }^{15}$ Agaricus blazei came from the family Agaricaceae. These plants can grow in tropical and subtropical regions, including Indonesia. ${ }^{16}$

Progesterone was found in the bulb of Allium cepa and tuber of Solanum tuberosum. ${ }^{17}$ Allium cepa comes from the family Liliaceae 


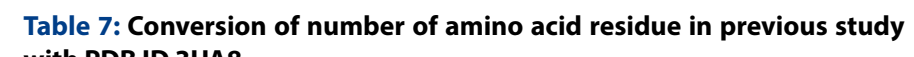
with PDB ID 3 UA8.

\begin{tabular}{|c|c|}
\hline $\begin{array}{l}\text { Reference } \\
\text { Amino acid }\end{array}$ & $\begin{array}{l}\text { Amino acid } \\
\text { PDB ID } 3 \text { UA8 }\end{array}$ \\
\hline GLU402 & GLU13 \\
\hline TYR450 & TYR61 \\
\hline PRO478 & PRO89 \\
\hline LEU479 & LEU90 \\
\hline THR480 & THR91 \\
\hline ARG485 & ARG96 \\
\hline THR686 & THR174 \\
\hline GLU705 & GLU193 \\
\hline SER654 & SER142 \\
\hline
\end{tabular}

Table 8: The result of visualization the interaction of herbal compounds with amino acid residues of macromolecule using LigandScout.

\begin{tabular}{cc}
\hline Compound & Amino Acid Residue Interaction \\
\hline Sanggenol O & Tyr16A, Met196A, Tyr61A, Arg96A, Ser142A, Ile11A, Thr195A, Tyr220A \\
Blazeispirol X & Tyr16A, Met196A, Tyr61A, Thr91A, Thr174A, Ala63A, Leu90A, Tyr220A, Leu109A \\
Progesterone & Met196A, Tyr61A, Arg96A, Thr91A, Thr174A, Leu138A \\
Nimolicinol & Tyr61A, Thr91A, Gly62A, Leu109A, Leu138A \\
Boeravinone F & Tyr61A, Pro89A, Thr91A, Ser142A, Glu193A, Tyr220A, Leu138A, Thr143A, Tyr190A \\
\hline
\end{tabular}

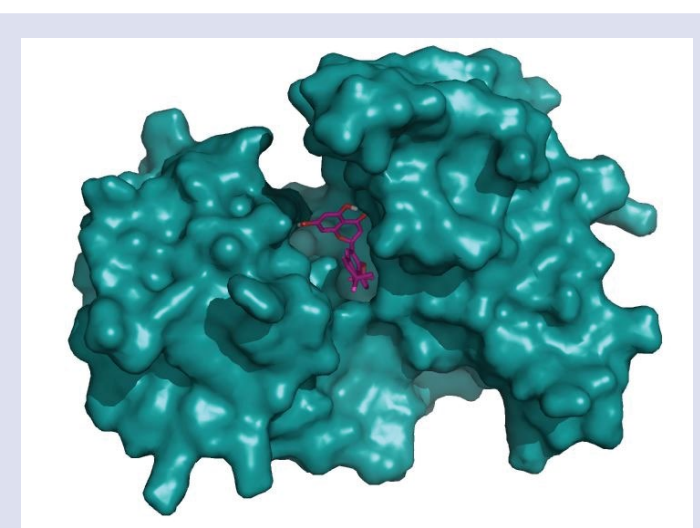

Figure 5: Sanggenol O with macromolecule 3 UA8.

and Solanum tuberosum comes from the family Solanaceae. Allium cepa and Solanum tuberosum grow a lot in Indonesia. Nimolicinol was a limonoid compound which isolated from the seeds of Azadirachta indica.$^{18}$ Azadirachta indica came from the family Meliaceae. Azadirachta indica grows in Java, Bali, Lombok and Sulawesi. ${ }^{19}$ Boeravinone F was a flavonoid of a boeravinone compound which isolated from the roots of Boerhavia diffusa and Mirabilis jalapa.$^{14}$ Boerhavia diffusa came from the family Nyctaginaceae and Mirabilis jalapa came from the family Sapindaceae. Boerhavia diffusa can grow in the tropic region. Mirabilis jalapa grow in Sulawesi, Nusa Tenggara, Maluku, Java, Bali and Lombok.

\section{CONCLUSION}

The database of a chemical compound of Indonesian herbal was compiled based on literature and KNApSAcK database. Compounds were made manually using MarvinSketch based on references from PubChem and KNApSAcK. The total structure of the compounds was 824 compounds. After a virtual screening, evaluation of ROF and analysis the interaction, five potential candidates of the active compound as an AMPA receptor antagonist have good permeation capabilities such as sanggenol $\mathrm{O}$, blazeispirol $\mathrm{X}$, progesterone, nimolicinol and boeravinone $\mathrm{F}$.

\section{ACKNOWLEDGEMENT}

Authors thank Universitas Indonesia for funding to this research through PITTA 2018 from Universitas Indonesia.

\section{CONFLICTS OF INTEREST}

The authors declare no affiliations with the organization or entity with a financial interest or without financial interest.

\section{ABBREVIATIONS}

ROS: Reactive Oxygen Species; HIF-1: Hypoxia-inducible Factor 1; BDNF: Brain-derived Neurotrophic Factor; AMPA: A-Amino-3Hydroxy-5-Methyl-4 Isoxazole Propionic Acid; NMDA: N-MethylD-Aspartate; CPU: Computer Processing Unit; GPU: Graphics Processor Unit; RAM: Random Access Memory; DUD-E: Directory of Useful Decoys-enhanced; RMSD: Root Mean Square Deviation; EF: Enrichment Factor; ROC: Receiver Operating Characteristics; AUC: Area Under Curve; ROF: Rule of Five; MW: Molecular Weight; HBA: Hydrogen Bond Acceptor; HBD: Hydrogen Bond Donor; RBC: Rotatable Bond Count. 


\section{REFERENCES}

1. Kementerian Kesehatan Republik Indonesia. Penyakit Jantung Penyebab Kematian Tertinggi, Kemenkes Ingatkan CERDIK [Internet]. 2017. http://www. depkes.go.id/article/view/17073100005/penyakit-jantung-penyebab-kematiantertinggi-kemenkes-ingatkan-cerdik-.html.

2. Pusat Data dan Informasi Kementerian Kesehatan Republik Indonesia. Situasi Kesehatan Jantung. Jakarta: Kementerian Kesehatan Republik Indonesia. 2013.

3. Wells B, DiPiro J, Schwinghammer T, DiPiro C. Pharmacotherapy Handbook. 9th ed. New York, N.Y: McGraw-Hill Education; 2015.

4. Kementerian Kesehatan Republik Indonesia. Presiden Resmikan RS Pusat Otak Nasional [Internet]. 2014.

5. http://www.depkes.go.id/article/view/201407200001/presiden-resmikan-rspusat-otak-nasional.html.

6. Halim H, Ibrahim N. Efek Neuroprotektif Ekstrak Akar Acalypha indica 500 mg/ kgBB terhadap Perubahan Inti Sel Saraf Hipokampus Pascahipoksia Serebri. Journal UI. 2013;1(2)

7. Bansal S, Sangha KS, Khatri P. Drug treatment of acute ischemic stroke. Am J Cardiovasc Drugs. 2013; 13(1): 57-69.

8. Padmanabhan B. Identification of novel modulators for ionotropic glutamate receptor, iGluA2 by in-silico screening. Theor Biol Med Model. 2013;10(1).

9. Weiser T. AMPA receptor antagonists for the treatment of stroke. Curr Drug Targets CNS Neurol Disord. 2005;4(2):153-9.

10. Lee K, Goodman L, Fourie C, Schenk S, Leitch B, Montgomery JM. AMPA Receptors as Therapeutic Targets for Neurological Disorders. In: Advances in Protein Chemistry and Structural Biology. 2016;203-61.
11. Yanuar A, Mun'im A, Lagho ABA, Syahdi RR, Rahmat M, Suhartanto H. Medicinal Plants Database and Three Dimensional Structure of the Chemical Compounds from Medicinal Plants in Indonesia. Int J Comput Sci. 2011;8(5):180-3.

12. Orain D, Ofner S, Koller M, Carcache DA, Froestl W, Allgeier H, et al. 6-Amino quinazolinedione sulfonamides as orally active competitive AMPA receptor antagonists. Bioorganic Med Chem Lett. 2012;22(2):996-9.

13. Veber D, Johnson S, Cheng H, Smith B, Ward K, Kopple K. Molecular Properties That Influence the Oral Bioavailability of Drug Candidates. Journal of Medicinal Chemistry. 2002;45(12):2615-23.

14. Pardridge WM. Drug transport across the blood-brain barrier. J Cereb Blood Flow Metab. 2012;32(11):1959-72.

15. Buckingham J, Munasinghe VRN. Dictionary of flavonoids. CRC Press: 2015;1199.

16. Hirotani M, Sai K, Kaneko A, Asada Y, Yoshikawa T. Biosynthetic studies on blazeispirane and protoblazeispirane derivatives from the cultured mycelia of the fungus Agaricus blazei. Tetrahedron. 2002;58(51):10251-7.

17. Karunarathna S. Mycosphere Essay 8: A review of genus Agaricus in tropical and humid subtropical regions of Asia. Mycosphere. 2016; 7(4): 417-39.

18. lino $M$, Nomura $T$, Tamaki $Y$, Yamada $Y$, Yoneyama $K$, Takeuchi $Y$, et al. Progesterone: Its occurrence in plants and involvement in plant growth. Phytochemistry. 2007;68(12):1664-73.

19. Lim TK. Edible medicinal and non medicinal plants. Flowers. 2014;8:1-1024

20. Sujarwo W, Keim AP, Caneva G, Toniolo C, Nicoletti M. Ethnobotanical uses of neem (Azadirachta indica A.Juss.; Meliaceae) leaves in Bali (Indonesia) and the Indian subcontinent in relation with historical background and phytochemical properties. J Ethnopharmacol. 2016;189:186-93.

Cite this article: Syahdi RR, Martinah CD, Yanuar A. Virtual Screening of Indonesian Herbal Database as $\alpha$-Amino-3-Hydroxy-5Methyl-4 Isoxazolepropionic Acid (AMPA) Antagonist. Pharmacog J. 2019;11(6):1204-10. 